\title{
Combined Coronary Artery Bypass Grafting, Aortic, and Lung Carcinoma Surgery
}

\author{
Nora Goebel ${ }^{10} \quad$ Ulrich F.W. Franke ${ }^{1}$ \\ ${ }^{1}$ Department of Cardiovascular Surgery, Robert Bosch Hospital, \\ Stuttgart, Germany \\ Thorac Cardiovasc Surg Rep 2020;9:e21-e23.
}

\begin{abstract}
Address for correspondence Nora Goebel, Robert Bosch Hospital, MD, Department of Cardiovascular Surgery, Auerbachstraße 110, Stuttgart 70376, Germany (e-mail: nora.goebel@rbk.de).
\end{abstract}

\author{
Abstract \\ Keywords \\ - combined surgery \\ - aortic \\ - coronary \\ - thoracic oncology \\ - clinical decision \\ making
}

Background Patients presenting with several cardiothoracic conditions that need to be addressed surgically require individual decision making as evidence remains inconclusive and combined surgical procedures carry an elevated perioperative risk. Case Description We present the case and management of a 73-year-old male with myocardial infarction due to three-vessel disease and left main stem stenosis, calcified aortic aneurysm, and right-sided non-small cell lung carcinoma.

Conclusion High-risk combined surgery should be indicated with scrutiny after individual consideration by an experienced heart team.

\section{Introduction}

For a widespread range of cardiothoracic diseases, we have already established evidence-based guideline recommendations. However, cases combining multiple cardiothoracic conditions, in particular cardiac, aortic, and onco-thoracic disease, still require individual decision making as evidence remains inconclusive. Herein we present a complex case from our clinic with critical discussion of the decisionmaking process and outcome.

\section{Case Description}

A 73-year-old male was referred to our center with a non-STelevation myocardial infarction (NSTEMI) due to a subtotal left main stem stenosis combined with a collateralized chronic occlusion of the right coronary artery, not applicable to percutaneous coronary intervention (-Fig. 1). As the chest radiograph showed a suspect opacity on the right side, and the patient reported cough and hemoptysis for the last 6 months, a thoracic computed tomography (CT) scan was performed and revealed a suspected bronchial carcinoma of the middle lobe, later confirmed by biopsy as non-small cell lung carcinoma. Staging by positron emission tomography-CT scan showed infiltration of the adjacent thoracic wall but no signs of lymph node or metastatic dissemination. Furthermore, a heavily calcified eccentric aneurysm of the ascending aorta with signs of contained rupture could be seen ( - Fig. 2A, B). Preoperative forced expiratory volume in 1 second was $72 \%$ but above the lower limit of normal. Echocardiography showed a preserved left and right ventricular ejection fraction.

\section{Clinical Problem}

For NSTEMI in three-vessel disease with left main stem stenosis and chronic total occlusion of the right coronary artery, this patient had a clear indication for coronary artery bypass surgery. ${ }^{1}$ With the eccentric ascending aortic aneurysm carrying a high risk of rupture, concomitant replacement of the ascending aorta and proximal arch would be indicated once undergoing cardiac surgery. The bronchial carcinoma should be resected as soon as possible, with a curative approach. ${ }^{2}$ The complete surgical approach in curative intention would comprise combined surgery of the ascending aorta, coronary artery bypass surgery, and lobectomy with partial thoracic wall resection-a truly high-risk operation with a EuroSCORE II of $18.16 \%$ plus the circumstance of malignant tumor surgery with the use of extracorporeal circulation.

\section{Treatment and Outcome}

After weighing the risks in interdisciplinary consultation of thoracic and cardiovascular surgeons, we decided on combined triple surgery with informed consent of the patient who expressed the wish to be treated. Intraoperatively,
License terms

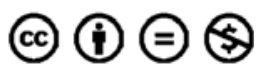

received

December 27, 2019

accepted

March 14, 2020
DOI https://doi.org/

10.1055/s-0040-1710321. ISSN 2194-7635. (c) 2020 Georg Thieme Verlag KG
Stuttgart · New York 


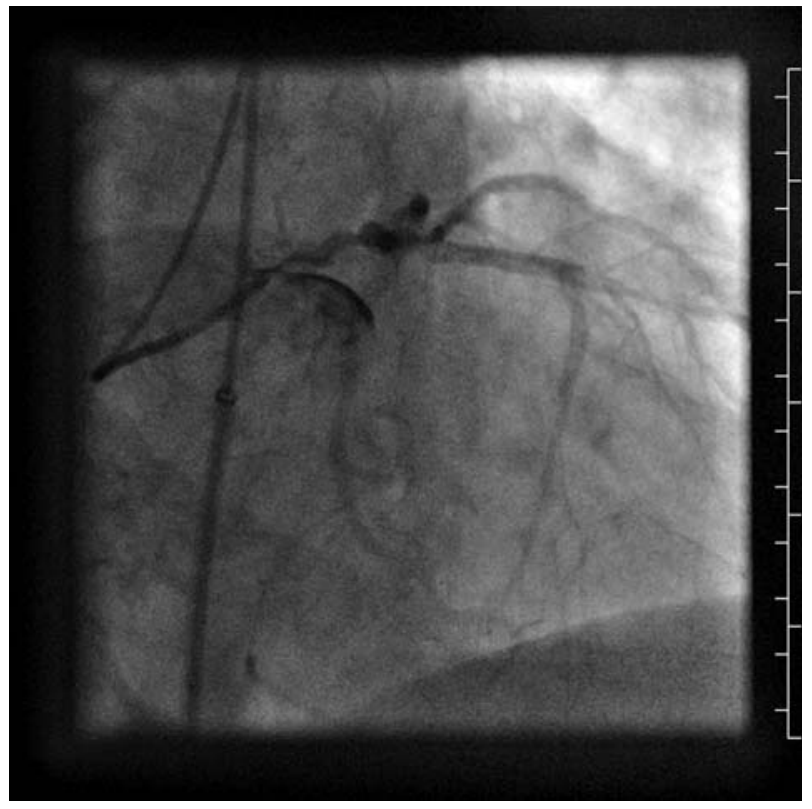

Fig. 1 Coronary angiography.

coronary bypass surgery was uneventful, as was the ascending and proximal aortic arch replacement with the help of short-term hypothermic circulatory arrest. During reperfusion we performed lung surgery with the help of additional thoracotomy. The lung carcinoma had infiltrated both the middle and upper lobe and the adjacent thoracic wall, so an upper bilobectomy and partial thoracic wall resection including the 5th rib was performed. Instantaneous histopathologic section confirmed R0 resection, lymph nodes were negative. Postoperative care was prolonged due to respiratory insufficiency and the need for noninvasive ventilation, but otherwise uncomplicated. Complete histopathologic analysis confirmed tumor stage: G3 pT3 pNO (27) LO V0
Pn0 R0. After an uneventful postoperative stay, the patient was able to be discharged directly to the rehabilitation clinic.

Unfortunately, during short-term follow-up the patient developed recurrent pleural effusion on the right side. Thoracoscopy revealed short-term tumor progress with carcinosis of the pleura. Palliative treatment was initiated. The patient died several months later, 10 months following the surgery.

\section{Discussion}

This case clearly illustrates the difficulties in clinical decision making when treating patients presenting with more than one severe and life-threatening cardiothoracic disease. Is it justified to deny high-risk surgical therapy to a patient who is an older, but not elderly, man, living independently and who has expressed his clear will and informed consent to full therapy? In our opinion, it was not. Is it ethically correct to recommend a complex and high-risk combined cardiothoracic surgery? Even with a EuroSCORE of $18 \%$ we did so as the tumor staging made a curative approach viable. A two-stage surgical approach (first cardiac, second thoracic) would have unnecessarily delayed oncological therapy with the risk of promoting tumor metastasis by the use of extracorporeal circulation. In vitro and in vivo studies have shown progression of tumor cell proliferation by cardiopulmonary bypass. ${ }^{3,4}$ The little evidence available of simultaneous treatment of cardiac and malignant disease from the literature is encouraging, especially in lung cancer stages I or II. Despite an elevated risk of bleeding, the simultaneous procedure is safe and feasible in lung cancer without mediastinal lymph node or metastatic involvement. ${ }^{4-8}$ Unfortunately, within short-term follow-up the patient suffered from early aggressive tumor progress with pleural carcinosis. In retrospect, one could raise the objection that a conservative and palliative approach might have given the patient more quality of life, but that remains speculative. One must not forget
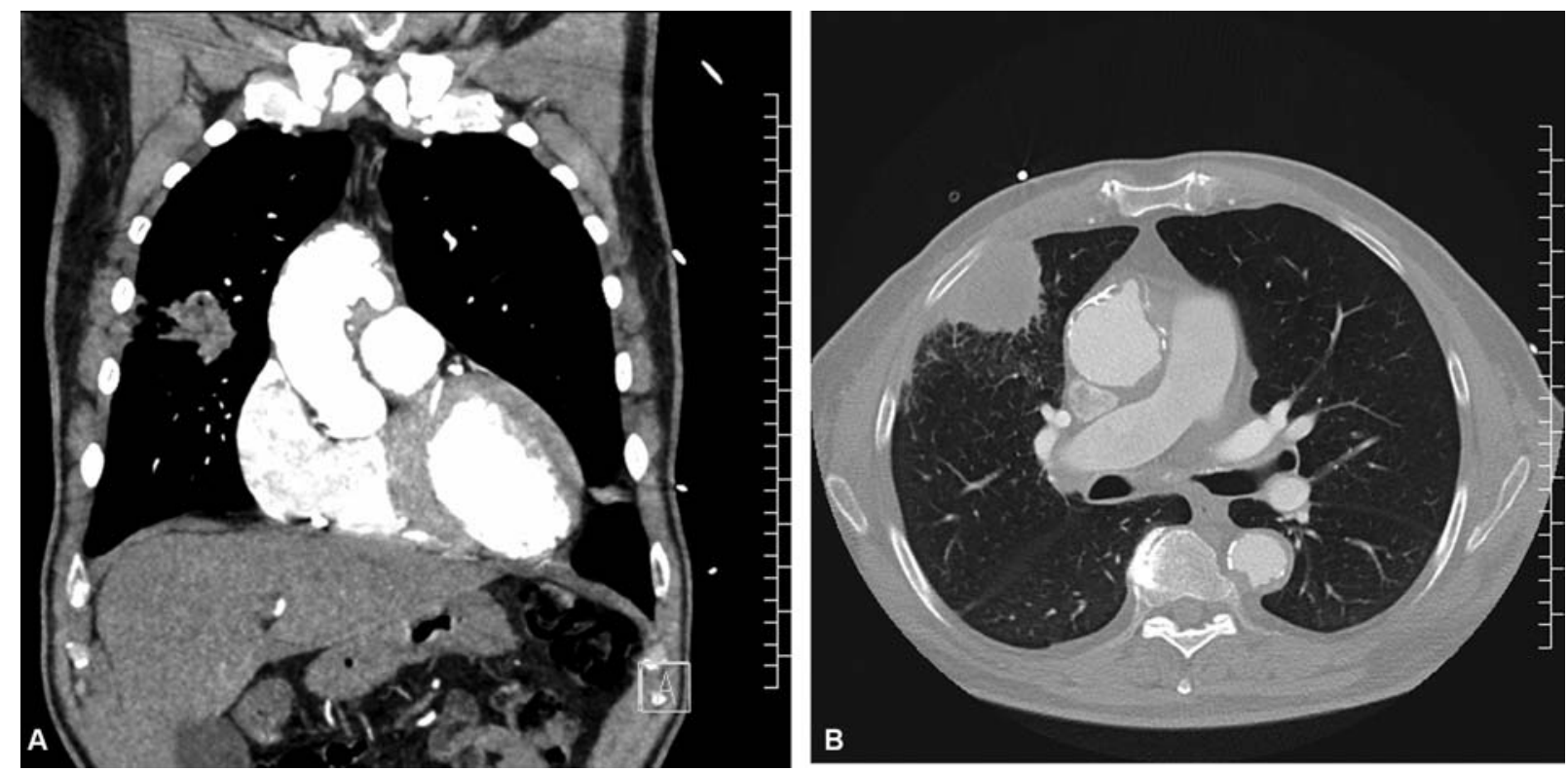

Fig. 2 Chest computed tomography. (A) Tissue window, coronary view: eccentric ascending/arch aortic aneurysm and right-sided lung carcinoma. (B) Lung window, transverse view: right-sided lung carcinoma with thoracic wall infiltration and eccentric ascending aortic aneurysm. 
that the patient suffered from his medical condition with exertional shortness of breath, cough, and hemoptysis. In addition, it is not possible to determine if the operation with the use of extracorporeal circulation might have triggered the progress somehow.

To conclude, it cannot be emphasized enough that indication for high-risk surgical procedures must take into consideration not only a patient's comorbidities, but also cocircumstances as well as their will and informed consent. As such, each case requires individual consideration by an experienced team of cardiac and thoracic surgeons.

\section{Conflict of Interest}

None.

\section{References}

1 Sousa-Uva M, Neumann FJ, Ahlsson A, et al; ESC Scientific Document Group. 2018 ESC/EACTS guidelines on myocardial revascularization. Eur J Cardiothorac Surg 2019;55(01):4-90
2 S3 Guideline Bronchial Carcinoma AWMF.(February 2018). Available at: https://www.awmf.org/uploads/tx_szleitlinien/020007OL_1_S3_ Lungenkarzinom_2018-03.pdf. Accessed October 27, 2019

3 Yamamoto S, Yoshimasu T, Nishimura Y, et al. In vitro evaluation of the effect of cardiac surgery on cancer cell proliferation. Ann Thorac Cardiovasc Surg 2011;17(03):260-266

4 Lorusso R, Vizzardi E, Johnson DM, et al. Cardiac surgery in adult patients with remitted or active malignancies: a review of preoperative screening, surgical management and short- and longterm postoperative results. Eur J Cardiothorac Surg 2018;54(01): $10-18$

5 Hosoba S, Hanaoka J, Suzuki T, et al. Early to midterm results of cardiac surgery with concomitant pulmonary resection. Ann Thorac Cardiovasc Surg 2012;18(01):8-11

6 Prokakis C, Koletsis E, Apostolakis E, et al. Combined heart surgery and lung tumor resection. Med Sci Monit 2008;14(03):CS17-CS21

7 Vojácek J, Hlubocký J, Burkert J, et al. Simultaneous cardiac and thoracic operations [in German]. Zentralbl Chir 2006;131(03):200-205

8 Tourmousoglou CE, Apostolakis E, Dougenis D. Simultaneous occurrence of coronary artery disease and lung cancer: what is the best surgical treatment strategy? Interact Cardiovasc Thorac Surg 2014;19(04):673-681 